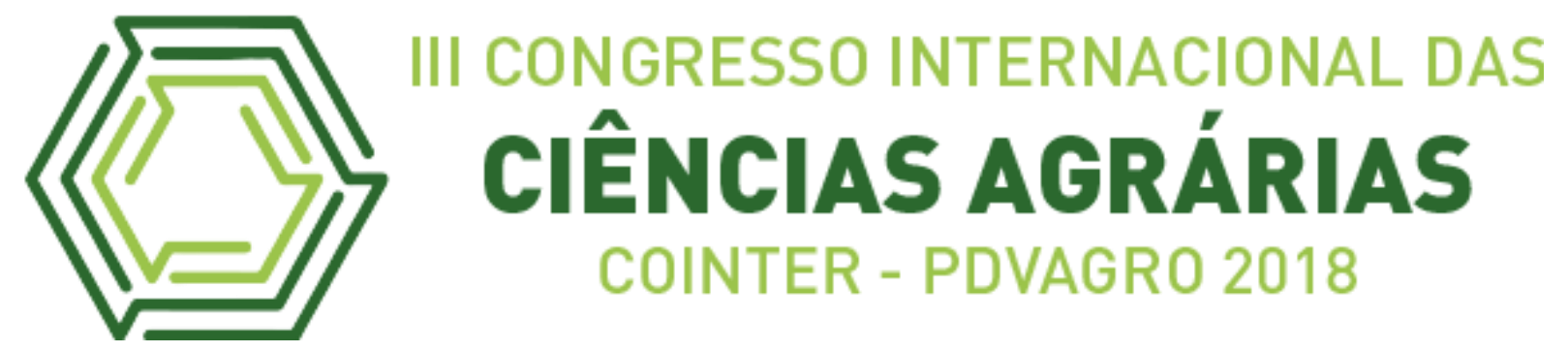

\title{
MANEJO E CONSERVAÇÃO DO SOLO: UMA PERCEPÇÃO DA COMUNIDADE RIACHO DO FIO NO MUNICÍPIO DE CODÓ-MA
}

\section{MANAGEMENT AND CONSERVATION OF THE SOIL: A PERCEPTION OF THE CONDUCT OF THE CABLE HARNESS IN THE MUNICIPALITY OF CODÓ-MA}

\author{
Apresentação: Relato de Experiência \\ Maksaíla Soares Gomes da Silva ${ }^{1}$; Maria Roselane Alves de Oliveira ${ }^{2}$; Cristiane Nunes \\ da Conceição ${ }^{3}$; Eulane Rys Rufino Abreu ${ }^{4}$; Daniel Barbosa Araújo ${ }^{5}$ \\ DOI: $\underline{\text { https://doi.org/10.31692/2526-7701.IIICOINTERPDVAGRO.2018.00744 }}$
}

\section{Introdução}

O uso inadequado do solo vem provocando deterioração em sua capacidade produtiva, principalmente nas terras que são utilizadas para fins agrícolas com o uso elevado da mecanização e a prática monocultura (MONDARDO, 1984). Dentre os principais problemas que o mal uso da terra traz, destacam-se a erosão hídrica, a qual colabora para o esgotamento de nutrientes, compactação, queimadas e contaminação pelos resíduos de agroquímicos, os quais advém do descarte das embalagens e/ou lavagem dos aplicadores em cursos d'aguas (ROCHA, PEREIRA, TEIXEIRA, 2014).

Diante disso, as práticas de conservação do solo tendem a minimizar a degradação do solo, conciliando a exploração econômica com a preservação dos recursos naturais do solo e água, uma vez que o solo desempenha papel relevante no ecossistema. (PRADO, 2014). Dentre as principais práticas destaca-se: rotação de culturas, plantio direto, ceifa do mato, cobertura morta, adubação verde; eliminação e controle do fogo.

Objetivou-se com o presente trabalho averiguar as práticas de manejo do solo exercidas pelos agricultores na comunidade Riacho do fio no município de Codó-MA.

\section{Relato de Experiência}

\footnotetext{
${ }^{1}$ Graduanda em Agronomia, IFMA- Campus Codó, maksailasoares@ outlook.com

2 Graduanda em Agronomia, IFMA-Campus Codó, roselany.alves@ hotmail.com

${ }^{3}$ Graduanda em Agronomia, IFMA- Campus Codó, cristianenunes2996@ gmail.com

${ }^{4}$ Graduanda de Tecnologia em Alimentos, IFMA- Campus Codó, eulanerys@ gmail.com

${ }^{5} \mathrm{Dr}^{\mathrm{o}}$ em Ciência do Solo, Universidade Federal do Ceará, daniel.araujo@ifma.edu.br
} 
O local do estudo foi à comunidade Riacho do Fio, a qual se localiza $12 \mathrm{~km}$ de distância da cidade de Codó-MA. Foram realizadas visitas, anotações e registros fotográficos. Além disso, aplicados 16 questionários com os agricultores da comunidade que cooperaram para o desenvolvimento desta pesquisa. O percentual dos entrevistados com faixa etária entre 41 e 50 anos foi de $23 \%$ e entre 61 a 70 anos de 35\%. Nas faixas etárias de 31 a 40 anos, 51 a 60 anos, e acima de 71, todos apresentaram 12\% e 6\% para aqueles com até 18 anos de idade.

Quanto ao nível de escolaridade, cerca de 69\% eram analfabetos, $13 \%$ possuíam o ensino fundamental incompleto, $12 \%$ ensino médio incompleto e $6 \%$ com ensino médio completo.

Dentre as principais culturas cultivadas na comunidade, $41 \%$ disseram arroz, feijão, mandioca e milho. Somente $23 \%$ cultivam o feijão, milho e mandioca, $6 \%$ com os mesmos percentuais cultivam arroz, feijão, milho e/ou arroz, milho, mandioca e/ ou feijão, milho, mandioca e, somente a cultura feijão. Quando questionados a respeito da destinação final da produção $71 \%$ responderem consumo próprio e $29 \%$ disseram serem destinados ao consumo e venda.

Em relação à limpeza da área para execução da atividade agrícola, 40\% dos agricultores utilizam a prática das queimadas como método prático de limpeza, $40 \%$ usam as ferramentas enxadas e/ou foices para limpeza da área e, outros $20 \%$ disseram que empregam herbicidas e roçadeiras e/ ou cortadeiras para limpeza da terra. Quando indagados a propósito do uso de agroquímicos $88 \%$ contaram que sim, utilizam nas plantações, principalmente, os herbicidas, e apenas $12 \%$ disseram não fazerem uso destes.

No que se refere o descarte de embalagens dos agroquímicos $35 \%$ dos entrevistados escolheram a opção "outros" justificando, por exemplo, que guardam em casa as embalagens vazias (Figura 1). Entretanto, 23\% responderam que deixam em locais a céu aberto, 12\% abandonam na própria lavoura e $6 \%$ dos relataram que descartam nos recursos hídricos. O uso inadequado dos agroquímicos ou descarte em locais impróprios é ocasionado pela falta de atenção nas orientações contidas nos rótulos ou bulas dos produtos (inseticidas, herbicidas e/ ou fungicidas entre outros) (GARCIA E ALVES FILHO, 2005).

No que diz respeito à proteção adequada na hora das aplicações destes, de acordo com a pesquisa, apenas $6 \%$ falaram que utilizam o avental antes da prática do campo, outros $12 \%$ dos moradores usam luvas, botas e máscaras, sendo que somente estes equipamentos não são suficientes para protegê-los de possíveis intoxicações, $29 \%$ disseram empregam somente 
botas e a maioria dos entrevistados $53 \%$ disseram que não utilizam nenhum tipo de equipamento de proteção.

Dentre as práticas conservacionistas do solo, $29 \%$ contaram que não realizam nenhuma dessas práticas. Entretanto, $24 \%$ dos agricultores relataram que evitam a prática das queimadas. Outros $23 \%$ descreveram que deixam a cobertura morta, os restos culturais, $12 \%$ aderem à prática de pousio, ou seja, descanso das terras cultivadas, e somente $6 \%$ disseram que realizam a rotação de culturas, trocando as culturas em cada novo plantio para evitarem o empobrecimento do solo.

Em relação ao tempo de cultivo numa mesma área, 53\% dos moradores narraram que cultivam apenas $1 \mathrm{vez}$ numa mesma área, $23 \%$ disseram que plantam 2 vezes. Com os valores semelhantes de $12 \%$ expuseram que cultivam 3 vezes e 5 vezes na mesma área. Por fim, foram indagados se utilizam a prática de rotação de culturas, ou seja, alternância das culturas na mesma área, e 65\% dos entrevistados disseram que não, no entanto, 35\% relataram usarem essa alternativa.

\section{Considerações}

Em vista disso, foram verificados que na comunidade do Riacho do fio que as principais culturas anuais que plantam são arroz, feijão, milho e mandioca. Para limpeza da área agrícola usam geralmente enxadas e/ ou foices.

A finalidade do cultivo é consumo próprio em que, habitualmente, utilizam os agroquímicos nas plantações que por vezes deixam as embalagens vazias destes agroquímicos a céu aberto e não usam equipamentos de proteção individual.

Por fim, as práticas conservacionistas utilizadas ao solo são: cobertura morta, evitando as queimadas e pousio, além do uso de rotações de culturas em que alternam as culturas anuais agrícolas numa mesma área as quais auxiliam na reciclagem de nutrientes do solo.

\section{Referências}

GARCIA, E. G.; ALVES FILHO, J. P. Aspectos de prevenção e controle de acidentes no trabalho com agrotóxicos. São Paulo: Fundacentro, 2005. 52 p. 
MONDARDO, A. Manejo e Conservação do Solo. Plantio Direto no Brasil. Fundação Cargill, p. 53-78, 1984.

PRADO, L. N. do. Incentivos financeiros para implementação de práticas conservacionistas do solo na bacia do Rio Canoinhas, Santa Catarina. UNIVERSIDADE FEDERAL DO PARANÁ. DISSERTAÇÃO DE MESTRADO. Curitiba, 2014. Disponível em: < https://www.floresta.ufpr.br/defesas/pdf_ms/2004/d681_0868-M.pdf.> Acesso em: 06 de julho de 2017.

ROCHA, M. S. D.; PEREIRA, E. S; TEIXEIRA. M. T. A Importância da Educação Ambiental na Gestão de Agrotóxicos na Agricultura Familiar no Município Colorado do Oeste, RO. V Congresso Brasileiro de Gestão Ambiental. Belo Horizonte, 2014. Disponível em: http://www.ibeas.org.br/congresso/Trabalhos2014/VII-115.pdf. Acesso em: 07 de agosto de 2017. 